\title{
Metodologia para projeto de planejamento estratégico de informações alinhado ao planejamento estratégico: a experiência do SenacPR
}

\author{
Denis Alcides Rezende \\ Professor do M estrado em G estão U rbana da Pontifícia U niversidade \\ Católica do Paraná - PU CPR \\ Doutor em gestão da tecnologia da informação (U FSC), mestre em \\ informática (U FPR), especialização em magistério superior, graduação \\ em administração de empresas e em processamento de dados. \\ www.netpar.com.br/drezende - drezende@netpar.com.br
}

\section{Resumo}

O objetivo desse artigo é descrever uma metodologia para projeto de Planejamento Estratégico de Informações (PEI) alinhado ao Planejamento Estratégico Organizacional, a partir de um estudo de caso no Serviço Nacional de Aprendizagem Comercial do Paraná, e os seus respectivos desafios e dificuldades. Os resultados e as contribuições relatam sobre a viabilidade prática do projeto $P E I$ e os detalhes da execução de sua metodologia. A conclusão reitera a importância da metodologia do PEl, implementada e aceita como uma ferramenta para contribuir de forma efetiva nas inteligências interna, competitiva e organizacional do Senac-PR.

\section{Palavras-chave}

Planejamento de informações; Planejamento estratégico; Alinhamento estratégico; Sistemas de informação; Tecnologia da informação.

\section{Methodology for information strategic planning project aligned with the business plan: Senac-PR's experience}

\section{Abstract \\ This paper aims to present and describe a methodology for Information Strategic Planning (ISP) project aligned to the Business Plan starting, from a case study in Senac-PR as well as its challenges and difficulties. The results and contributions show the feasibility of this ISP Project and the detailing of the methodology execution. The conclusion reiterates the importance of the ISP methodology implemented and accepted as a tool to contribute in an effective way in the Senac-PR's internal, competitive and organizational intelligences.}

\section{Keywords}

Information planning; Business plan; Strategic alignment; Information systems; Information technology.

\section{IN TRO DU Ç Ã O}

Pesquisar, organizar e implementar uma metodologia de planejamento estratégico de informações para alinhar os seus emergentes e estratégicos recursos tecnológicos aos serviços prestados de educação profissional requer exaustivos exercícios práticos embasados em sólida fundamentação teórica. Esses exercícios estão relacionados às atividades cotidianas, dinâmicas e inteligentes dos planejamentos estratégicos da organização, de marketing e da tecnologia da informação (TI). Tais atividades devem ser elaboradas de forma integrada e estruturadas, com informações oportunas e conhecimentos personalizados, fatores essenciais para a gestão inteligente das organizações de serviços educacionais.

A estruturação das informações e a disponibilização compartilhada dos conhecimentos não acontecem da noite para 0 dia e exigem das organizações de serviços educacionais os referidos planejamentos a curto, médio e longo prazo.

E como atualmente as organizações de serviços educacionais enfrentam um ambiente competitivo, globalizante e turbulento, elas necessitam realizar sua reestruturação, reorganização, flexibilização, adaptação e modificação de forma política, social, ambiental e econômica, para continuarem presentes e crescentes no mercado. N esse contexto, o relevante papel da TI deve ser revisto.

A partir da estruturação das informações e da disponibilização compartilhada dos conhecimentos organizacionais personalizados, a TI e seus recursos podem agregar valores aos serviços das organizações de serviços educacionais, auxiliando a promoção das suas inteligências competitiva e organizacional (Luftman; Brier, 1999; M eador, 1997).

0 alinhamento estratégico dos serviços educacionais e da TI é muito importante para a perenidade dessas organizações, principalmente quan do ele é utilizado como uma ferramenta de gestão. M uitos são os fatores que em conjunto levam ao sucesso essa atividade, sejam 


\section{Denis Alcides Rezende}

humanos, comportamentais, sociais, culturais, políticos, ambientais, organizacionais, sistêmicos e tecnológicos (Luftman; B rier, 1999; C arruthers, 2000).

0 objetivo desse artigo é descrever uma metodologia para projeto de planejamento estratégico de informações alinhado ao planejamento estratégico, a partir de experiência elaborada (estudo de caso) no Serviço $\mathrm{N}$ acional de A prendizagem Comercial (Senac-PR), e os seus respectivos desafios e dificuldades.

O Senac-PR é uma instituição de educação profissional aberta a toda a sociedade. Responde à Confederação $\mathrm{N}$ acional do Comércio. É uma organização privada sem fins lucrativos. Recebe $1 \%$ da arrecadação destinada à Previdência Social (IN SS). Presta serviços particulares e também públicos (serviços educacionais a comunidades carentes).

\section{REVISÃO DA LITERATURA}

Esse capítulo resgata e resume os principais conceitos que envolvem 0 trabalho elaborado. No caso do Senac$P R$, o planejamento estratégico é elaborado pela Senac $\mathrm{N}$ acional, que abrange todos os estados (unidades da federação). Esse planejamento nacional é desmembrado no planejamento de marketing de serviços de cada Senac nos seus respectivos estados, considerando os preceitos de inteligência empresarial ou organizacional.

\section{Planejamento estratégico (PE)}

O PE, ou planejamento estratégico empresarial, é um processo dinâmico e interativo para determinação de objetivos, políticas e estratégias (atuais e futuras) das funções empresariais ou organizacionais e dos procedimentos das organizações. É elaborado por meio de técnicas administrativas de análise do ambiente (interno e externo), das ameaças e oportunidades, dos seus pontos fortes e fracos, que possibilita aos gestores estabelecer um rumo para as organizações, buscando um certo nível de otimização no relacionamento entre a organização e o meio ambiente que a cerca, formalizado para produzir e articular resultados, na forma de integração sinérgica de decisões e ações organizacionais (Boar, 1993; Vasconcelos \& Pagnoncelli, 2001; M intzberg \& Q uinn, 2001).

\section{Planejamento de marketing de serviços (PMS)}

O PMS é um desmembramento do PE que visa a consolidar um conjunto de atividades relacionadas com o mercado, integrando esforços de toda a organização por intermédio de seus colaboradores. Deve especificar detalhados programas de marketing para atender aos objetivos organizacionais, respeitando a sua realidade financeira e de capacitação humana. Contempla implementações dos planos de mercado-alvo, produtos ou serviços, metas de lucro, preço, distribuição e orçamentos (Kotler, 1998).

\section{Planejamento estratégico de informações (PEI)}

O PEI é um processo dinâmico e interativo para estruturar estratégica, tática e operacionalmente as informações organizacionais, a TI (e seus recursos: hardware, software, sistemas de tel ecomunicações, gestão de dados e informações), os sistemas de informação (estratégicos, gerenciais e operacionais), as pessoas envolvidas e a infra-estrutura necessária para 0 atendimento de todas as decisões, ações e respectivos processos das organizações (Premkumar \& King, 1992; Boar, 1993; Kearns \& Lederer, 1997).

\section{G overnança pública e política (G PP) do terceiro setor}

0 entendimento e as aplicações dos conceitos de GPP (M arques, Cunha \& M eirelles, 2002) podem contribuir no alinhamento proposto. A pesar de as concepções teóricas de governança serem multifacetadas, estão ocorrendo mudanças substanciais dos conceitos tradicionais baseados no princípio da autoridade estatal para abordagens de governança. Assim, são contempladas novas tendências de gestão compartilhada e interinstitucional que envolvem o setor público, o setor produtivo e o crescente setor voluntário ou terceiro setor (Frey, 2002).

A nova governança pública também pode ser chamada de new public management (N PM ) que pressupõe aplicar nas organizações públicas os modelos de gestão originalmente oriundos da iniciativa privada e os conceitos de administração estratégica, de competitividade e de empreendedorismo (0 sborne \& $G$ aebler, 1992). Também tem como princípios: reestruturação, reengen haria, reinven ção, realinhamento e reconceituação (Jones \& Thompson, 2000).

A pesar de o Senac-PR não ser uma organização pública, ele aplica os conceitos de e-governança, que pode ser entendida como a aplicação dos recursos da TI na gestão das organizações públicas e do terceiro setor. Esse conceito, juntamente com o de NPM, está contemplado no modelo proposto de alinhamento entre o PEI e o PE. 


\section{Alinhamento do PEI ao PE}

0 alinhamento entre 0 PEI e o PE se constitui a partir das relações verticais, horizontais, tran sversais, dinâmicas e sinérgicas das funções empresariais ou organizacionais. Promove o ajuste ou a adequação estratégica das tecnologias disponíveis de toda a organização, como uma ferramenta de gestão organizacional contemplada pelos conceitos de qualidade, produtividade, efetividade, modernidade, perenidade, rentabilidade, inteligência competitiva e inteligência organizacional (H enderson \& Venkatraman, 1993; Boar, 1993).

0 alinhamento entre PEI e PE é um processo contínuo e complexo. Não há uma só estratégia ou uma só combinação de atividades que permitirão às organizações alcançar e sustentar esse alinhamento, pois são fatores em conjunto que levam ao sucesso dessa atividade (Luftman \& Brier, 1999). A lém disso, cada organização tem seu próprio processo de desenvolvimento de capacidades e competências essenciais que são abrangidas respectivamente pelo seu próprio, específico e personal izado contexto (C iborra, 1997). A integração do $\mathrm{PEI}$ ao $\mathrm{PE}$ envolve recursos humanos e não-humanos (Boynton, Jacobs \& ZmuD, 1992).

0 modelo de alinhamento proposto contempla os seguintes construtos e suas variáveis adequadas à organização: tecnologia da informação; sistemas de informação e do conhecimento; pessoas ou recursos humanos; contexto organizacional ou infra-estrutura (Rezende, 2002 e 2003).

\section{Cultura de informações e de conhecimentos}

0 processo de aculturação de informações e de conhecimentos nas organizações será mais facilitado e efetivo, se os seus gestores e clientes (ou usuários) estiverem conscientes e plenamente envolvidos com a $\mathrm{TI}$ e seus recursos e aplicações. Em caso contrário, essa aculturação será mais lenta e difícil, poden do causar muitos transtornos às organizações.

As informações dentro das organizações passam por ciclos evolutivos, até serem plenamente estruturadas e disponibilizadas na forma de conhecimentos compartilhados. Esses ciclos evoluem em estágios crescentes e também diferentes para cada organização (Prahalad \& Hamel, 1990; N olan, 1993; Santos et alii, 2001).
Inteligência empresarial ou organizacional (IEO)

A IEO se constitui de um valor estratégico inexorável nas organizações que a adotam como parte de seu modelo de gestão, no qual suas funções empresariais ou organizacionais devem estar inter-relacionadas com a utilização da TI (Santos et alii, 2001).

$\mathrm{Na}$ IEO estão contemplados os conceitos de modelagem estratégica de negócios, de inovação, de competitividade, de inteligência competitiva e de gestão do conhecimento. Dessa forma, conceitua-se IEO como a somatória dos conceitos de inovação, criatividade, qualidade, produtividade, efetividade, perenidade, rentabilidade, modernidade, inteligência competitiva e gestão do conhecimento (Santos et alii, 2001, Rezende, 2002).

\section{METODOLOGIA DA PESQUISA E MODELO DE ALINHAMENTO}

Esse trabalho tem sido elaborado desde 2000. $\mathrm{Na}$ primeira fase, aplicou-se a metodologia predefinida, cuja abordagem contemplou as variantes qualitativa e quantitativa. Caracterizou-se como uma pesquisa exploratória e descritiva de um survey em 78 grandes organizações brasileiras, com as atividades elaboradas de preparação, definição, realização preliminar e realização final.

$\mathrm{N}$ a segunda fase, foi elaborado um estudo de caso no Senac-PR. 0 método de estudo de caso individual pretendeu responder sobre a viabilidade de executar 0 modelo proposto de alinhamento entre 0 PEI e 0 $\mathrm{PE}$, em um contexto real ( $\mathrm{N}$ achmias \& $\mathrm{N}$ achmias, 1987; Yin, 1994).

De acordo com a revisão da literatura e com a reestruturação e documentação das vivências profissionais do pesquisador, com 15 anos em atividades empresariais e acadêmicas, o modelo proposto de alinhamento entre o PEI e o PE pode ser sustentado principalmente por quatro grandes grupos de fatores ou recursos sustentadores: tecnologia da informação (TI); sistemas de informação e do conhecimento (SI); pessoas ou recursos humanos $(\mathrm{RH})$; contexto organizacional $(\mathrm{CO})$. Possui três dimensões: PEI e seus recursos e ferramentas; PE e seus negócios ou atividades organizacionais; recursos sustentadores do alinhamento $\mathrm{PEI}$ ao $\mathrm{PE}$. As dimensões são desmembradas em construtos: alinhamento estratégico entre PEI e PE; TI, SI, RH e CO. Cada construto possui suas respectivas variáveis (Rezende, 2002). 


\section{Denis Alcides Rezende}

\section{METODOLOGIA DE PLANEJAMENTO ESTRATÉGICO DE INFORMAÇÕES}

Constitui-se de uma abordagem organizada para atingir objetivos por meio de passos preestabelecidos. A metodologia deve ser de toda a organização e para toda a organização, de maneira que seja elaborada e utilizada por todos. Ela deve ser amplamente discutida e detalhadamente avaliada por todos na organização. Também pode ser revisada, atualizada e complementada na medida do desenvolvimento dos projetos.

As premissas da metodologia são a modularidade e sua própria existência. As justificativas do desenvolvimento de projetos por meio de metodologias devem ser formalizadas, de modo a que seus produtos forneçam a visão do estado do projeto a qualquer instante; sirvam como meio de comunicação entre os envolvidos; indiquem o nível de participação de todos os envolvidos; detalhem nos níveis adequados aos interesses da equipe envolvida; mantenham um histórico documental do projeto; sejam sempre bases para as fases e subfases seguintes. Todas essas justificativas reiteram a importância de uma metodologia de desenvolvimento estruturado de projetos.

A metodologia requer seu desmembramento em fases, essas, por sua vez, em subfases, as quais geram um ou mais produtos que devem ser avaliados e aprovados pela equipe. As avaliações do projeto são os momentos de apresentação e de aprovação para toda a equipe multidisciplinar do projeto, para verificação do grau de satisfação e atendimento às necessidades e aos requisitos do projeto, obedecendo aos padrões de efetividade, qualidade e produtividade estabelecidos.

D eve sempre ser elaborada em equipe multidisciplinar (comitês ou células de negócios) atuando de forma interdisciplinar. Esta equipe multidisciplinar reúne talentos de diversas áreas e funções da organização, somando conhecimentos para geração de produtos consistentes. Todos os componentes devem possuir seus respectivos planos de trabalho, individuais e coletivos. O s principais papéis da equipe são patrocinador, gestor, clientes ou usuários (ligados ao negócio) e executores (técnicos da TI).

0 projeto pode ser dividido em (três) grandes partes: capa; apresentação do conteúdo e da organização; desenvolvimento. A terceira parte descreve todas as fases e subfases, nas quais são gerados e aprovados os respectivos produtos. As fases são mostradas de forma seqüencial e didática, nas chamadas "partes". As subfases de cada parte podem ser elaboradas concomitantemente e de forma integrada e complementar. 0 nível de detalhamento de cada subfase deve ser determinado pela equipe multidisciplinar ou comitê do projeto, de acordo com o grau de necessidade da organização e do momento em que ela se encontra.

Para a elaboração de algumas fases, recomenda-se a criação de formulários para documentar as respectivas atividades.

A metodologia PEI (planejamento estratégico de informações) aplicada no Senac-PR foi composta de nove partes. Pode-se elaborar o projeto pela seqüência das partes sugeridas ou com as subfases agrupadas por finalidade, tais como organizar o projeto, identificar e avaliar determinados itens, propor ou planejar determinados itens, executar o planejamento e outras subfases. As fases e tarefas podem ser adequadas, complementadas ou suprimidas. Foram elaboradas as seguintes fases e subfases:

\section{Parte I. Planejar o PEI}

Essa parte foi direcionada para a organização preliminar do projeto e para a constituição da equipe multidisciplinar e suas competências. Foi desenvolvida juntamente com a Parte 9, G erir PEI (que é elaborada ao longo do projeto), com as seguintes subfases:

a) Organizar o projeto (nominar a equipe multidisciplinar ou comitê do PEI; definir objetivos do $\mathrm{PEI}$; definir metodologia do PEI);

b) C apacitar a equipe de trabalho (proporcionar aquisição da competência ou capacitação; estabelecer e distribuir as atividades). Foram constituídas e capacitadas duas equipes: a primeira, composta por todos os diretores e gerentes das 18 unidades de negócio do Paraná que atuavam mais como aprovadores do projeto. 0 diretor regional atuou como patrocinador, as gerentes das unidades de marketing, planejamento e TI como gestoras do PEI. Foram elaborados três encontros de capacitação e trabalho em ambiente externo, envolvendo representantes de todas as unidades de negócio do Paraná. O utra pequena equipe (comitê executivo) atuou cotidianamente e detalhou as etapas do PEI, sendo composta por quatro usuários de TI de diferentes áreas e por três técnicos de TI.

\section{Parte II. Revisar o planejamento estratégico}

Essa parte foi relacionada com a revisão do planejamento estratégico do Senac Nacional e do planejamento de marketing de serviços do Senac-PR, com as seguintes subfases: 
c) Identificar estratégias e ações organizacionais (definir negócio e missão empresarial ou organizacional; definir visão e valores organizacionais; definir objetivos e estratégias organizacionais; relatar objetivos das funções organizacionais; relatar políticas e normas organizacionais; analisar ambiente interno e externo; avaliar estrutura organizacional atual; definir objetivos da área ou unidade da TI; prever o perfil profissional; elaborar planos de ação). 0 planejamento estratégico do Senac Nacional e o planejamento de marketing de serviços do Senac-PR foram revistos e complementados com pequenos ajustes. Essas atividades foram executadas com facilidade, tendo em vista que os referidos planejamentos haviam sido elaborados recentemente.

\section{Parte III. Planejar informações e conhecimentos}

Essa parte foi relacionada com a complementação dos planejamentos da Parte II, visando a preparar a Parte IV, a partir da modelagem das necessidades de informações oportunas e de conhecimentos personalizados do SenacPR, com as seguintes subfases:

d) Identificar informações e conhecimentos organizacionais (elaborar o modelo de informações empresariais ou organizacionais (MIE); mapear conhecimentos). Essa parte foi uma das mais trabalhosas, pois contemplou seis funções empresariais ou organizacionais (produção e serviços, comercial e marketing, materiais elogística, finanças, recursos humanos e jurídico-legal). Foram elaborados 180 M IEs com mais de seis mil itens de informação nos níveis operacional, gerencial e estratégico, envolvendo as 18 unidades de negócio do Paraná. Depois de uma análise detalhada, foram consolidados em 155 M IEs com 5.364 informações documentadas sem redundância. Foram elaborados apenas alguns mapas de conhecimentos. Esses mapas serão re elaborados na segunda edição do PEI em 2004.

\section{Parte IV. Avaliar e planejar sistemas de informação e de conhecimentos}

Essa parte foi direcionada para a identificação e para análise de todos os atuais sistemas de informação e de conhecimentos do Senac-PR. Como conseqüência, foram ajustados ou propostos e planejados novos sistemas de todos os tipos e níveis, com as seguintes subfases:

e) Avaliar sistemas de informação e de conhecimentos atuais (elaborar plano de trabalho; identificar todos os sistemas da organização; relatar detalhes dos sistemas existentes; avaliar e sumariar a situação geral dos sistemas); f) Planejar sistemas de informação e de conhecimentos (rever e detalhar informações e conhecimentos; identificar e nominar os sistemas propostos; desenhar o modelo conceitual ou elaborar o modelo de dados ou os diagramas; descrever as funções ou requisitos dos sistemas propostos; validar sistemas propostos; avaliar aquisição ou desenvolvimento dos sistemas; elaborar quadro geral dos sistemas propostos). Foram avaliados 286 módulos de sistemas, com formulários oriundos das 18 unidades de negócio do Paraná, incluindo formulários, planilhas, documentos e os sistemas existentes. D epois de uma análise detalhada, a partir de critérios de índices de atendimento e satisfação, foram consolidados em 272 módulos sistêmicos em 13 grandes sistemas atuais. Excluídos os sistemas existentes, foram identificados e detalhados 12 grandes sistemas propostos com seus subsistemas e respectivos módulos: gestão de clientes e prospects (e dois subsistemas); gestão acadêmica (e 13 subsistemas); gestão de marketing (e seis subsistemas); gestão orçamentária (e três subsistemas); gestão da estrutura do regional (e três subsistemas); gestão de materiais didáticos e multimeios (e cinco subsistemas); gestão logística administrativa (e cinco subsistemas); gestão de recursos humanos (e dois subsistemas); gestão de empresas pedagógicas (e sete subsistemas); portal Senac-PR (e quatro subsistemas); sistemas internos da TI (e cinco subsistemas); sistemas de informação geren cial e estratégico. 0 s dados contidos nos sistemas atuais serão migrados para as bases de dados dos novos sistemas, visan do a manter consistências, bases históricas, e interromper definitivamente 0 uso dos sistemas atuais. U ma arquitetura compatível com as necessidades de flexibilidade, de reaproveitamento e de serviços para usuários foi proposta em três camadas: de apresentação ou do usuário; de negócio; de dados.

\section{Parte V. Avaliar e planejar tecnologia da inform ação}

Essa parte foi direcionada à identificação e para a análise de todos os recursos atuais da tecnologia da informação do Senac-PR. Como conseqüência, foram ajustados ou sugeridos novos recursos tecnológicos necessários para atender a todos os sistemas propostos, com as seguintes subfases:

g) A valiar tecnologia de informação (elaborar plano de trabalho; identificar TI existente; descrever e avaliar software e utilitários atuais; descrever e avaliar hardwaree periféricos atuais; descrever e avaliar sistemas de telecomunicações atuais; descrever e avaliar gestão de dados e informação atual; descrever e avaliar plano de contingência, logística, segurança, auditoria e demais 


\section{Denis Alcides Rezende}

políticas de TI; elaborar quadro demonstrativo geral da TI disponível).

h) Planejar tecnologia de informação - software, hardware, sistemas de telecomunicação, gestão de dados e informação (desenvolver a estratégia dos componentes da TI; definir a política de gestão, operação, aquisição e legalização dos componentes da $\mathrm{Tl}$; definir os sistemas de controle de acesso e dos níveis de acesso aos componentes da TI; planejar a forma de cópias de dados e esquema de backup dos componentes da TI; planejar a forma de guarda de dados e esquema de segurança dos componentes da TI; planejar a forma de recuperação de informações; definir o sistema de atualização, instalação e manutenção dos componentes da TI; desenvolver os critérios de controle, segurança, auditoria e avaliação permanente dos componentes da TI; elaborar o plano de contingência e de reserva técnica dos componentes da TI; elaborar quadro geral dos componentes da $\mathrm{Tl}$ ).

Foram identificados 1.003 computadores utilizados como estações de trabalho, 10 servidores, 1.046 monitores de vídeo, 227 impressoras e 19 scanners, distribuídos nas 18 unidades denegócio. São 4.918 diferentes tipos desoftware utilizados com respectivas licenças de uso. O s sistemas de telecomunicações estão distribuídos entre as 18 unidades por meio de uma rede framerelay na topologia estrela (as unidades do interior estão ligadas diretamente a C uritiba). C ada unidade possui uma sala (ou ambiente separado) onde estão instalados os equipamentos (roteadores, centrais de telefone e outros). A gestão de dados é determinada por planos de elaboração e guarda de dados (cópias), da recuperação dos dados, de controle de acesso e de níveis de navegação nas informações. São elaboradas cópias dos arquivos dos usuários, do banco de dados, do Exchange, inclusive em 31 fitas com um esquema de rotatividade.

As políticas de TI do Senac-PR foram reavaliadas e sugeriram-se algumas melhorias. Elaboraram-se diversos planos de atualizações e de aquisições do parque de TI, para aten der os sistemas e os software propostos do SenacPR, distribuídos em três opções de arquitetura dehardware (servidores e estações de trabalho). Também se contemplaram os aumentos dos recursos dos sistemas de telecomunicações e da gestão de dados e informações. As políticas de TI foram complementadas com as recomendações sugeridas nas subfases anteriores.

i) Avaliar infra-estrutura paralela (elaborar plano de trabalho; identificar toda a infra-estrutura paralela a TI existente; descrever e avaliar a infraestrutura paralela existente; descrever e avaliar políticas de infraestrutura paralela; elaborar quadro demonstrativo geral da infraestrutura paralela);

j) Planejar infra-estrutura paralela (desenvolver a estratégia da infra-estrutura paralela; definir a política de gestão, operação, aquisição e legalização da infraestrutura paralela; planejar e descrever a infra-estrutura paralela; definir o sistema de atualização, instalação e manuten ção da infra-estrutura paral ela; desenvolver os critérios de controle, segurança, auditoria e avaliação permanente; elaborar o plano de contingência e de reserva técnica; elaborar quadro geral da infraestrutura paralela). Juntamente com os recursos da TI, foi avaliada toda a infra-estrutura paralela das 18 unidades principalmente quanto às obras civis, salas, cabeamentos e sistemas de proteção e segurança (aterramentos, no-breaks, estabilizadores, pára-raios, ar condicionado e outros). D iversas sugestões foram elaboradas. Elaboraramse diversos planos de atualizações e de aquisições da infra-estrutura paralela de todas as unidades contemplando essas principais recomendações: efetuar revisões periódicas nos itens dessa subfase, para garantir a operabilidade e diminuir riscos; acompanhar atualizações de acordo com as necessidades. As políticas de TI do Senac-PR foram complementadas com as recomendações dessa subfase.

k) Organizar a unidade da tecnologia da informação (elaborar plano de trabalho; avaliar unidade da tecnologia da informação; definir estratégias da unidade da tecnologia da informação; definir modelo de gestão da unidade da tecnologia da informação; definir políticas da TI; definir normas e padrões técnicos operacionais da TI; propor estrutura organizacional da $\mathrm{TI}$; elaborar quadro geral da TI e dos valores humanos necessários). Essa subfase retratou o quadro atual da unidade (Gerência) da TI, para fundamentar uma proposta de sua reestruturação em termos de estrutura organizacional e funcional, assim como caracterizar as necessidades de recursos humanos para alinhar a atuação dessa unidade ao novo modelo de gestão do Senac-PR. Foi descrito um mapa de oportunidades, ameaças, pontos fortes e fracos. D efiniu-se a missão da unidade da TI: prover todos os recursos necessários de infraestrutura de TI para o desempenho e progresso da instituição, adotando o projeto PEI como ferramenta norteadora das ações de TI e dos demais planos organizacionais. A tuará como assessora e prestadora de serviços e de soluções de TI alinhadas ao negócio. A dotará o modelo de gestão participativa. Redefiniu sua estrutura organizacional e sua política de atuação. 


\section{Metodologia para Projeto de Planejamento Estratégico de Informações...}

\section{Parte VI. Avaliar e planejar recursos humanos}

Essa parte foi direcionada para a análise dos atuais perfis de recursos humanos do Senac-PR. Como conseqüência, foram identificados e planejados novos perfis de recursos humanos necessários para atender a todos os sistemas propostos e toda a tecnologia da informação proposta. Foram elaboradas as seguintes subfases:

I) Avaliar recursos humanos (elaborar plano de trabalho; identificar e descrever as funções ou cargos existentes; identificar e descrever o perfil profissional atual dos valores humanos; avaliar competências e habilidades dos RH envolvidos no projeto e da organização; rever estrutura organizacional; avaliar processos de recrutamento e seleção de profissionais da organização; avaliar processos de capacitação e de competências atual; elaborar quadro demonstrativo da avaliação dos recursos humanos);

m) Planejar recursos humanos gestores e "nãogestores" (propor estratégias dos recursos humanos; propor estrutura organizacional para toda a organização; definir e descrever o novo perfil profissional e papéis das pessoas na organização; identificar e planejar necessidades de capacitação; propor processos de recrutamento e seleção de pessoas; propor processos de capacitação e de competências dos recursos humanos; propor políticas de gestão de pessoas; elaborar quadro geral dos recursos humanos necessários). A avaliação e o planejamento dos perfis de recursos humanos (juntamente com a descrição de cargos e funções e 0 plano de cargos e salários) foram trabalhados com facilidade, tendo em vista que essas atividades tinham sido elaboradas recentemente para atender 0 planejamento estratégico do Senac $\mathrm{N}$ acional e 0 planejamento de marketing de serviços do Senac-PR.

\section{Parte VII. Priorizar e custear PEI}

Essa parte foi direcionada para a priorização, custeio e impactos do PEI do Senac-PR, a partir da avaliação e planejamento dos sistemas, da tecnologia da informação e dos recursos humanos. Foram elaboradas as seguintes subfases:

n) Estabelecer prioridades e necessidades (definir metodologia de prioridades para execução do PEI; elaborar quadro de pontuação para desenvolvimento ou aquisição e de implantação do $\mathrm{PEI}$; relatar os recursos necessários para execução do PEI);

o) Avaliar impactos (prever como as atividades de todos os envolvidos no projeto afetarão a organização; identificar as medidas para preparar a organização para os novos SI e a nova $\mathrm{TI}$; relatar os impactos positivos e negativos; desenvolver alternativas para minimizar os impactos; elaborar quadro de condições e recomendações);

\section{p) Elaborar plano econômico-financeiro} (desenvolver a estratégia e políticas de retorno dos investimentos; elaborar análise de custos, benefícios (mensuráveis e não-mensuráveis), riscos e viabilidade; avaliar eventuais custos de implementação ou otimização e outros; sintetizar o plano econômico-financeiro).

A priorização foi elaborada de acordo com dois momentos. No primeiro, utilizaram-se fatores que poderiam influen ciar na elaboração dos sistemas, e, após sua pontuação, produziu-se um quadro com as prioridades sob a óptica das necessidades dos negócios do Senac-PR e respectivas complexidades. T rês fatores foram utilizados: grau de necessidade, grau de depen dência, grau de complexidade (gerando o grau de priorização = necessidade (-) dependência (-) complexidade). No segundo momento, utilizaram-se apenas fatores de necessidade de negócios, considerando 0 atendimento e alinhamento ao planejamento estratégico do Senac $\mathrm{N}$ acional e o planejamento de marketing de serviços do Senac-PR. Para a análise de impactos do PEI, elaborouse uma relação de pontos positivos, pontos negativos e alternativas ou recomendações dos seguintes impactos: cultural e comportamental, tecnológico, orçamentário, legal, de desempenho organizacional e de gestão organizacional. 0 plano econômico-financeiro foi elaborado a partir dos orçamentos específicos do Senac $\mathrm{N}$ acional e 0 do Senac-PR. Receberam prioridades os recursos humanos e tecnológicos requeridos para a execução do PEl.

\section{Parte VIII. Executar PEI}

Essa parte foi direcionada para a execução do PEI propriamente dito no Senac-PR, a partir da elaboração das partes anteriores. Foram elaboradas as seguintes subfases:

q) Elaborar planos de ação (elaborar cronogramas para o desenvolvimento ou aquisição e implantação do PEI; desmembrar o cronograma em diferentes atividades internas e externas; elaborar planos de implantação, de ação e de investimento consolidados). A partir das políticas e estratégias para a TI, focadas em quatro princípios (atualização contínua da infra-estrutura a TI; desempenho institucional; soluções de TI voltadas ao negócio; desenvolvimento de competências internas), definiram-se sete grandes objetivos: aumentar o grau de 


\section{Denis Alcides Rezende}

capacitação técnica e profissional da equipe de TI (com duas metas); aumentar a efetividade no desenvolvimento de soluções de TI (com três metas); aumentar a efetividade na gestão de projetos de TI (com duas metas); implementar programa de capacitação de colaboradores (com três metas); desenvolver os sistemas de informação propostos pelo $\mathrm{PEI}$, mantendo a aderência aos demais planejamentos (com dez metas); manter atualizada e aumentar o grau de segurança da infraestrutura da rede corporativa de telecomunicações e de telefonia (com seis metas). Para cada meta foram descritas as suas respectivas ações de curto, médio e longo prazo.

\section{Parte IX. G erir PEI}

Essa parte foi elaborada em todas as outras fases, ou seja, no início, no desenvolvimento e na conclusão. Ela foi iniciada juntamente com a primeira parte, constituindo atividades vitais para o sucesso do PEI no Senac-PR. Foram elaboradas as seguintes subfases:

r) Gestionar, divulgar, documentar e aprovar o projeto (definir a forma de gestão do projeto; divulgar o projeto; gerir o projeto; elaborar dicionário de termos do projeto $\mathrm{PEI}$; elaborar, finalizar e revisar o relatório final do projeto $\mathrm{PEI}$; avaliar projeto $\mathrm{PEI}$; apresentar o projeto ao comitê do projeto ou equipe multidisciplinar). Para gerir o projeto PEI, o Senac-PR começou a atuar antes do próprio início do mesmo, em reuniões de diretoria e de colaboradores, juntamente com 0 desenvolvimento do seu planejamento de marketing de serviços. A gestão participativa adotada definiu estratégias e ações com atividades e tempos predeterminados. Para tanto, elaborou um plano de comunicação e divulgação (informativos de atividades do PEI, atas de trabalho, documentos e textos na intranet, relatórios para diretoria etc.), plano de reuniões (internas e externas, individuais e coletivas), planos de trabalho (cronogramas), apresentações e avaliações permanentes da efetividade, qualidade e produtividade do projeto.

\section{O N C LU SÃ 0}

A conclusão deste trabalho relata a dificuldade para definir, organizar e aplicar uma metodologia de planejamento estratégico de informações e da TI, visando a alinhar os seus emergentes e estratégicos recursos tecnológicos aos serviços prestados pelo Senac-PR.

Este artigo sintetizou o desafio dos exaustivos exercícios práticos, a partir da fun damentação teórica na viabilização da integração dos planejamentos propostos, os quais exigiram dos grupos de trabalho muita dedicação e dinamismo nas suas atividades cotidianas para superar as inúmeras dificuldades encontradas, sejam organizacionais, culturais, tecnológicas ou humanas. A realidade cotidiana diagnosticada no survey das 78 organizações participantes na primeira fase mostra a que a estruturação das informações oportunas e 0 compartilhamento dos conhecimentos personalizados não acontecem facilmente do dia para a noite e exigem planejamentos, estratégias, ações e decisões de curto, médio e longo prazo. No Senac-PR, na segunda fase deste projeto, esse quadro não foi diferente.

O bservou-se, na execução do projeto, que a competência, a vontade e o esforço das pessoas envolvidas, trabal hando em conjunto, fizeram 0 alinhamento proposto acontecer e viabilizaram a metodologia de PEI proposta. Essa observação ficou evidenciada no relato da Partel . A Parte II do projeto não apresentou dificuldades, pois o Senac $\mathrm{N}$ acional já havia elaborado o seu planejamento estratégico e o Senac-PR o seu planejamento de marketing de serviços. A Parte III e a Parte IV foram as mais desafiadoras, principalmente porque as pessoas no SenacPR não estavam habituadas a trabalhar com informações oportunas, personalizadas e sistematizadas. A ParteV não causou impactos, porque o Senac-PR já possuía adequados recursos de $\mathrm{TI}$ e respectivas infra-estruturas. A Parte VI não contemplou os novos perfis profissionais necessários, conforme a metodologia exigia, optando apenas pela descrição de cargos e funções. As outras partes não apresentaram maiores dificuldades e impactos. As demais recomendações e conclusões foram descritas nos resultados (produtos externados) de cada parte realizada no projeto PEI (item 4. M etodologia PEI ). Portanto, essas conclusões responderam metodologicamente sobre a viabilidade de executar o modelo proposto de alinhamento entre o PEI e o PE, em um contexto real do estudo de caso elaborado.

As contribuições deixam claro que, na prática, é possível viabilizar 0 alinhamento proposto do planejamento estratégico do Senac nacional e de marketing de serviços do Senac-PR ao Planejamento Estratégico da TI, resgatando assim a visão moderna da TI alinhada aos serviços educacionais e atuando como uma ferramenta colaboradora dos negócios dessa organização. Em especial, destacam-se os seguintes ben efícios ou vantagens para o Senac-PR, como resultados ou fatores de sucesso alcançados: conhecer o caminho a ser trilhado; melhorar a integração e as parcerias com os clientes ou usuários; melhorar a compreensão dos problemas dos clientes ou usuários e da unidade de $\mathrm{TI}$; melhorar a competência e capacitação dos envolvidos com o projeto; melhorar entendimento sobre a organização e sua inteligência competitiva e organizacional. 


\section{M etodologia para Projeto de Planejamento Estratégico de Informações...}

Para a academia, este trabalho pode contribuir nos estudos teóricos e práticos, principalmente no que tange às metodologias para desenvolvimento e implantação de PEI, ou Information Technology Planning, com foco no alinhamento de planejamentos empresariais ou organizacionais e de planejamentos de marketing, bem como, no diferente modelo de alinhamento proposto, com suas diferentes peculiaridades, variáveis, convergências e divergências, pontos fortes e fracos.

Destacam-se as seguintes dificuldades encontradas no Senac-PR: entendimento e aceitação da metodologia que envolveu toda a organização, em que os clientes (usuários de TI) tinham de se envolver e elaborar uma série de atividades planejadas; mudança de cultura e valores organizacionais, em que a equipe do projeto e os demais colaboradores tiveram de compartilhar e tran sferir dados, informações e principalmente conhecimentos; ajustes forma de atuação da equipe da unidade da TI, que necessitou de adequações na sua postura de prestador de serviços internos e na articulação de pactos positivos com os usuários de TI. Como erros do projeto, os quais serão ajustados na segunda versão do mesmo, podem ser mencionados: a divulgação e o marketing do projeto foram insuficientes; a equipe cliente perdeu a visibilidade dos resultados no final do projeto; as prioridades não foram seguidas de forma efetiva; as novas técnicas e métodos não foram discutidos suficientemente, causando estresse no momento de sua implantação.

O utras pesquisas e outros estudos podem ser elaborados a partir deste, principalmente os direcionados a melhorar as propostas trabalhadas, seja nos métodos científicos, no modelo de alinhamento sugerido, na metodologia PEI proposta, ou também como respostas para novas questões com a inclusão de outras organizações e outros projetos.

Ainda, a partir dos resultados auferidos neste projeto, 0 maior desafio dos gestores do Senac-PR é fazer com que a TI desempenhe seu relevante papel estratégico, agregando valores aos seus serviços e auxiliando a promoção das suas inteligências competitiva e organizacional. Dessa forma, a U nidade da TI do Senac$P R$ adotou as seguintes orientações estratégicas e operacionais: utilizar o PEI como ferramenta norteadora das ações de TI, com alinhamento ao planejamento estratégico do Senac nacional, ao planejamento de marketing de serviços do Senac-PR e demais planos operacionais; efetivar a aderência aos planejamentos do Senac-PR por meio da participação efetiva do $\mathrm{ClO}$ nessas atividades da alta administração, fazendo com que a unidade da TI atue como assessora e prestadora de serviços e de soluções de TI, tendo como prioridade contribuir efetivamente com as necessidades de negócios do Senac-PR; atuar de acordo com o modelo de gestão participativa, negociando suas atividades com o grupo gestor responsável ou com os grupos de usuários de TI e aceitando as prioridades determinadas por esses grupos; definir de forma permanente um comitê com equipe multidisciplinar com planos de trabalho definidos; primar por iniciativas da unidade da TI que norteiem os seus esforços na agregação de valores estratégicos ao Senac-PR e que determinem os focos de atenção a serem cumpridos.

A conclusão reitera a importância da metodologia do PEI atuando como uma ferramenta para contribuir de forma efetiva nas atividades operacionais, táticas e estratégicas do Senac-PR, em que as palavras-chave foram vontade, informação e planejamento.

\section{REFERÊ N C IAS}

BOAR, B. H. Theart of strategic planning for information technology: crafting strategy for the 90s. [S. I.] : John Wiley, 1993.

BOYNTON, A. C.; JACOBS, G. C; ZMUD, R. W. Whose responsibility is IT management?. Sloan $M$ anagement Review, p. 32-38, Summer 1992.

CARRUTHERS, T. E. O ccupational psychology. Journal of O ccupational and O rganizational Psychology, Leicester, v. 73, p. 380-381, Sept. 2000.

CIBORRA, C. De profundis ? Deconstructing the concept of strategic alignment. In: IRIS CONFERENCE, 20., 1997, N orway. Proceedings... N orway : U niversity of O slo, 1997.

FREY, K. Governança eletrônica: experiências de cidades européias e algumas lições para países em desenvolvimento. In: EISEN BERG, J.; CEPIK, M. (O rg.). Internet e política: teoria e prática da democracia eletrônica. Belo Horizonte : U FM G, p. 141-163, 2002.

HENDERSON, J. C.; VENKATRAMAN, N. Strategic alignment: leveraging information technology for transforming organizations. IBM Systems Journal, v. 32, n. 1, p. 4-16, 1993.

KEARNS, G.; LEDERER, A. Alignment of IS plan with business plan: the impact on competitive advantage. In: AIS, 1997, Indianapolis. Proceedings... Indianapolis : [s. n.], 1997.

KOTLER, P. Administração de marketing: análise, planejamento, implementação e controle. 5. ed. São Paulo : Atlas, 1998.

JONES, L. R.; THOM PSON, F. U m modelo para a nova gerência pública. Revista do Serviço Público, v. 51, n. 1, p. 41-79, 2000.

LU FTMAN, J. N.; BRIER, T. A chieving and sustaining business-IT alignment. California M anagement Review, Berkeley, v. 42, p. 109-122, Fall 1999.

MARQUES, E. V.; CUNHA, M. A.; M EIRELLES, F. S. Modelos de gestão de tecnologia de informação no setor público brasileiro. In: EN CONTRO ANUAL DA ANPAD, 26., 2002, Salvador. Anais... Salvador: AN PAD, 2002.

MEADOR, L. C. IT/ strategy alignment - identifying the role of information technology in competitive strategy. (W orking paper $n$. 9403). Disponível em: <http:// www.it-consultancy.com/ background/ alignment/ index.html >. A cesso em: 21 out. 1997. 


\section{Denis Alcides Rezende}

MINTZBERG, H.; QUINN, J. B. 0 processo da estratégia. 3. ed. Porto Alegre : Bookman, 2001.

NACH M IAS, D.; N ACH M IAS, C. Research methods in the social sciences. 3. ed. N ew York : St. M artin, 1987.

NOLAN, R. L. N ote on information technology and strategy. Boston : H arvard Business School, 1993.

OSBORNE, D.; GAEBLER. T. Reinventing government: how the entrepreneurial spirit is transforming the public sector. Reading, MA: Addison-W esley, 1992.

PRAHALAD, C. K.; HAMEL, G. The core competence of the corporation. Harvard Business Review, p.79-91, M ay-June 1990.

PREMKUMAR, G.; KING, W. R. An empirical assessment of information systems planning and the role of information systems in organizations. Journal of M anagement Information Systems, Armonk, v. 9, p. 99, Fall 1992.
REZEN DE, D. A. Planejamento de sistemas de informação e informática: guia prático para planejar a tecnologia da informação integrada ao planejamento estratégico das organizações. São Paulo : A tlas, 2003.

Tecnologia da Informação integrada à inteligência empresarial: alinhamento estratégico e análise da prática nas organizações. São Paulo: A tlas, 2002.

; ABREU, A. F. Tecnologia da informação aplicada a sistemas de informação empresariais: 0 papel estratégico da informação e dos sistemas de informação nas empresas. 3. ed. São Paulo : Atlas, 2003.

SANTOS, A. R. et al. (O rg.). G estão do conhecimento: uma experiência para 0 sucesso empresarial. Curitiba : Champagnat, 2001.

VASCON CELOS FILHO, P.; PAGN O N CELLI, D.C onstruindo estratégias para vencer: um método prático, objetivo e testado para o sucesso da sua empresa. Rio de Janeiro : C ampus, 2001.

YIN, R. K. Case study research: design and methods. London : Sage Publications, 1994. 